\title{
Climate Change and Extreme Events: an Assessment of Economic Implications
}

\author{
Alvaro Calzadilla* Francesco Pauli ${ }^{\dagger}$ and Roberto Roson ${ }^{\ddagger}$
}

26th April 2005

\begin{abstract}
We use a dynamic general equilibrium model of the world economy to assess the economic implications of vulnerability from extreme meteorological events. In particular, we consider the impact of climate change on ENSO and NAO circulation patterns, and the implied variation on regional expected damages. Two effects are taken into account: (1) short-term impacts, due to changes in the demand structure, generated by higher/lower precautionary saving, and (2) variations in the regional economic growth paths.
\end{abstract}

JEL Codes: D58, Q51, Q54.

Keywords: Computable General Equilibrium, Climate Change, Extreme Events.

\section{Introduction}

Extreme events and climate change are often found associated in the popular press, TV and Hollywood movies. Yet, scientific evidence on the causal link between climate change and natural disasters is weak, to say the least. Global Circulation Models, used to forecast future climate scenarios, typically fail in identifying extreme events, because they produce average climatic conditions for relatively large areas, whereas disasters may occur in small areas and in short time periods.

On the other hand, extreme weather conditions naturally occur throughout the world, independently of the climate change. The mere definition of extreme event, that is, what can be considered extreme and what cannot, depends on the context; exceptional weather conditions in some regions may not be so exceptional in other regions. In this paper, we shall take a pragmatic stance, by considering to be an extreme event any event that has produced relevant economic damages somewhere in the world, and it has been recorded as such in a specific data-base.

A few studies have recently tried to identify the possible role of climate change in influencing the frequency of some extreme events in some regions. One stream of

\footnotetext{
*EEE Programme at the Abdus Salam ICTP, Trieste, Italy

${ }^{\dagger}$ University of Padua, Italy

${ }^{\ddagger}$ Fondazione Eni Enrico Mattei and Ca’Foscari University of Venice, Italy
} 
research focuses on the climate change impact on oceanic circulation patterns, like the El Niño Southern Oscillation (ENSO) and the North Atlantic Oscillation (NAO). The state of oceanic circulation plays a role on weather conditions through the circulation of cold and warm water streams. In turn, a changing climate may affect the type and frequency of different states in the natural oscillations.

This paper builds upon Pauli (2004), who estimated expected damage from extreme events in the three ENSO regimes (warm, cold, neutral). We combine this study with a forecast of ENSO and NAO events in the presence of climate change.

Our approach is a purely statistical one. We look for evidence of a statistical relationship between temperature levels and states of oceanic circulation, but we do not rely on any physical model of causation, simply because such a model does not exist at the present state of scientific knowledge. Only limited information on a few phenomena could possibly be embodied into the statistical model. ${ }^{1}$

Economic consequences of extreme weather normally occur through losses in primary production inputs: human resources, physical capital, infrastructure, land endowments and productivity. All these induce higher costs and prices, with varying incidence among industries and regions. Because of trade linkages and capital flows, local effects propagate throughout the world economy, causing systemic effects and structural adjustments.

In addition, increased (or decreased) likelihood of extreme events per se generates economic consequences. To the extent that people become aware of higher climate vulnerability, consumption habits change and, for example, more insurance services are bought. This may already be seen in those regions that are more frequently affected by phenomena like tornados or earthquakes. Insurance against adverse weather may be acquired directly, by buying insurance products on the market, or indirectly, through precautionary saving or mandatory contributions to public insurance schemes. The aggregate effect of all these actions is to increase savings and decrease current consumption. In turn, higher saving rates make the economy growing faster, but only up to the point in time where the negative shock possibly materializes.

We present here some findings of a research aimed at investigating these issues, using a computable general equilibrium model of the world economy. This study is itself part of a larger project, dealing with economic impacts of climate change in several dimensions (sea level rise, human health, tourism, water availability, energy demand, etc.).

The paper is organized as follows. In the next section, a statistical analysis linking climate change, oceanic circulation patterns, and expected damage from extreme events is presented. Results of this analysis are used to conduct simulation exercises with the computable general equilibrium model of the world economy. This model is introduced in section 3. Subsequently, a section discusses the short term effects of higher or lower precautionary saving. Section 5, on the other hand, consider the impact of higher or lower expected damages on the regional economic growth. A final section draws some conclusions.

\footnotetext{
${ }^{1}$ Technically, some results could be driven by ex-ante information. For example, a link between climate change and some phenomena (e.g., earthquakes) could be ruled out as implausible.
} 


\section{Statistical Assessment of Disaster Burden}

We assess the frequency of natural disasters in a changing climate environment in two steps. In the first step, we link natural disaster frequency to the state of two important oceanic circulation cycles: the El Niño Southern Oscillation (ENSO) and the North Atlantic Oscillation (NAO). In the second step, we estimate the probability of occurrence of the three ENSO states and the two NAO states, as a function of global temperature variation.

The ENSO phenomenon (Trentberth (1997)) is a periodic change in the climatic state of the Pacific basin. The climate pattern naturally oscillates between a normal phase, in which the surface of Pacific ocean is warm $\left(29-30^{\circ} \mathrm{C}\right)$ in the West and cold in the East $\left(22-24^{\circ} \mathrm{C}\right)$, a positive, and a negative phase. During the positive, or warm, phase, also called El Niño, the East Pacific is warmer than the West Pacific and the sea level pressure is higher in the West Pacific, leading to a change in the direction of trade winds across the tropical Pacific. During the negative, or cold, phase, also called La Niña, the East Pacific is colder than the West to an unusual extent and the sea level pressure is higher in the East Pacific.

ENSO effects on weather are stronger in the tropical Pacific basin, but spread to other regions of the world (IPCC (2001) and Meehl et al. (2000)). The existence of a relationship between the occurrence of natural disasters throughout the world and the ENSO state has been suggested, among others, by Nicholls (1998) and Mason (2001). Bouma et al. (1997) analyses the correlation between natural disasters and ENSO states at a global scale, finding significant variations in the incidence of extreme events during different ENSO phases. Sardeshmukh et al. (2000) point out that ENSO may be more important for extreme events than for average climate conditions.

The North Atlantic Oscillation (Wanner et al. (2001)) refers to the pattern of atmospheric circulation in the North Atlantic region. It can be stated in terms of differences between sea level pressure measured in the Azores islands and pressure measured in Iceland. A positive NAO phase is said to occur when this difference is high, whereas negative NAO phases are associated with small pressure differentials (not necessarily negative).

Positive and negative NAO phases appear to be associated with different weather conditions. In particular, precipitation patterns over North Atlantic and Europe seem to be strongly affected by the state of the North Atlantic Oscillation (Hurrell (1995)).

We use data on disasters taken from the EM-DAT disaster database ${ }^{2}$. EM-DAT collects information about catastrophic events occurred since $1900^{3}$, but we consider only

\footnotetext{
${ }^{2}$ EM-DAT: The OFDA/CRED International Disaster Database - www.cred.belemdat - Université Catholique de Louvain - Brussels - Belgium. The Emergency Events Database (EM-DAT) is maintained since 1988 by the Collaborating Centre for Research on the Epidemiology of Disasters (CRED) and is made available to the public on the above website. This is one of three international disasters databases. The other ones belong to Swiss Re (Sigma) and Munich Re (NatCat) and are not publicly available. The three databases have relevant differences (Sapir and Below (2002)), but EM-DAT appears to be the most suited for the purpose of scientific analysis, as the other two sources are more business oriented and their construction methodology is not revealed to the public.

${ }^{3}$ Information sources include UN agencies, non-governmental organisations, insurance companies, research institutes and press agencies.
} 
records of natural disasters from 1960 to $2001 .{ }^{4}$ For each event the type of disaster ${ }^{5}$, the region ${ }^{6}$, the number of victims (people killed and people affected) and the damage are recorded (though data is sometimes missing).

In order to estimate the relationship between ENSO and NAO states and the number of disasters we fit, for each disaster type and region of the world, a Generalized Additive Model (Hastie and Tibshirani (1990)) where the response variable $N_{d r t}$ is the number of natural disasters of type $d$ during year $t$ in region $r$

$$
\left.N_{d r t} \sim \text { Poisson }\left(\exp \left\{f_{d r}(t)+\beta_{d r} W_{t}+\gamma_{d r} C_{t}+\delta_{d r} N_{t}\right)\right\}\right) .
$$

$W_{t}\left(C_{t}\right)$ is a dummy variable equal to one if ENSO is in a warm (cold) phase during year $t$ and zero otherwise, $N_{t}$ is a dummy variable equal to one if $\mathrm{NAO}$ is in the positive state during year $t$ and zero otherwise.

The function $f_{d r}$ is estimated as a spline with two degrees of freedom, and it allows for a possibly non linear time trend. ${ }^{7}$ The impact of ENSO and NAO states on the frequency of disasters of type $d$ in region $r$ is measured by the coefficients $\beta_{d r}, \gamma_{d r}$ and $\delta_{d r}$. For instance, a positive and significant value of $\beta_{d r}$ means that, during warm ENSO, the frequency of disaster type $d$ in region $r$ is higher than in the neutral ENSO phase.

We estimated the model (1) for droughts, epidemics, cold and heat waves, floods, slides, waves and surges, wild fires and wind storms occurring in specific subcontinental regions. A statistically significant impact of ENSO and/or NAO states has been found for a number of event types. In these cases, we can compute the expected number of events, conditional on ENSO and NAO states: $E\left(N_{d r t} \mid W_{t}=i, C_{t}=j, N_{t}=k\right)$ for $i, j, k=0,1(i, j$ not simultaneously equal to 1 but possibly simultaneously 0$){ }^{8}$

We then consider a second model, on the relationship between temperature variation and frequency of ENSO phases. The existence of such a connection is suggested by Hunt (2001), who reports evidence on relative frequency of ENSO states, during periods characterized by different temperature variations. As it can be seen in figure 2, warm ENSO events appear to be more likely the higher the rate of increase of temperature (measured as variation in a century: $\Delta T$ ). We use linear interpolation in order to estimate the probability of warm and cold phases for different values of $\Delta T$, thus obtaining the functions $P\left(W_{t}=1 \mid \Delta T\right) ; P\left(C_{t}=1 \mid \Delta T\right)$ depicted in figure 2 .

An analogous model is used to forecast the frequency of NAO states. Many authors have explored the possible factors driving NAO oscillation, to understand whether the upward trend of the NAO index (Dickson et al. (2003)) and the persistence of the

\footnotetext{
${ }^{4}$ An event is included in the data set if: (1) it caused more than 10 deaths or (2) at least 100 people had been affected (requiring immediate assistance) or (3) local authorities either declared an official emergency state or required external assistance.

${ }^{5}$ In EM-DAT disasters are classified as: droughts, earthquake, epidemics, cold and heat waves, famine, floods, insect infestations, slides, volcanoes, waves/surges, wild fires and wind storms.

${ }^{6}$ Regional classification in EM-DAT: Central Africa, East Africa, North Africa, Southern Africa, West Africa, North America, Central America, South America, Caribbean, South Asia, South-East Asia, West Asia, East Asia, European Union, Russian Federation, Rest of Europe, Oceania.

${ }^{7}$ This is found for almost all disaster types and regions. It may be due to increasing accuracy of the database, increasing population density and wealth. The presence of a time trend prevents us from using a model relating directly disaster burden and global temperature.

${ }^{8}$ The time component $f(t)$ is held fixed at the value estimated for 2001 .
} 


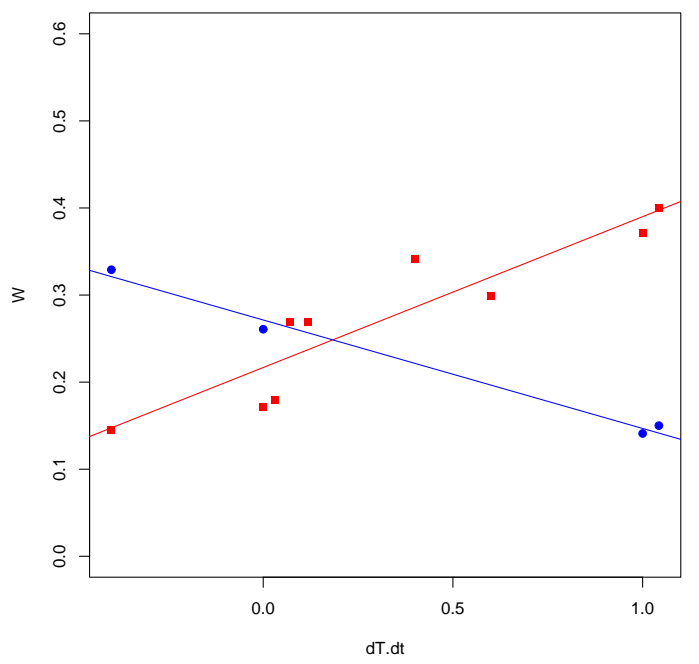

Figure 1: Relative frequency of the three ENSO states as a function of the temperature variation (variation in a century).

positive phase in recent years may be due to an anthropogenic effect. In particular, the connection between NAO and greenhouse gases emissions and that between NAO and the sea surface temperature have been investigated. According to Gillett et al. (2003) anthropogenic greenhouse gases and sulphate aerosols emissions have had an effect on sea level pressure in the last fifty years. Shindell et al. (1999) obtain similar results, as well as a correlation between the NAO index and the recent rise in land temperatures in the northern hemisphere. Visbeck et al. (2001) considers a number of studies on this subject, but concludes that a precise explanation of the process is not available at the moment. Hoerling et al. (2001), on the other hand, detect a link between NAO and the warming of tropical sea surface temperature, where the latter is the cause and NAO is the effect. This result is also obtained by Bojaru and Gimeno (2003).

On the basis of the findings above, we estimated a logistic generalized linear model, where the probability of NAO being positive is modeled as a function of global temperature. Results of the fitting (weakly significant from a statistical point of view) are graphically displayed in figure 2 .

Combining the results of the three models, the expected number of disasters per year, on the basis of global temperature $T$ and temperature variation $\Delta T$, can be obtained:

$$
\begin{aligned}
E\left(N_{t} \mid T, \Delta T\right)= & \sum_{i, j, k} E\left(N_{t} \mid W_{t}=i, C_{t}=j, N_{t}=k\right) \times \\
& \times P\left(W_{t}=i, C_{t}=j \mid T, \Delta T\right) P\left(N_{t}=k \mid T, \Delta T\right)
\end{aligned}
$$

where $i, j, k$ are 0 or 1 (but $i$ and $j$ cannot be both equal to 1 ). 


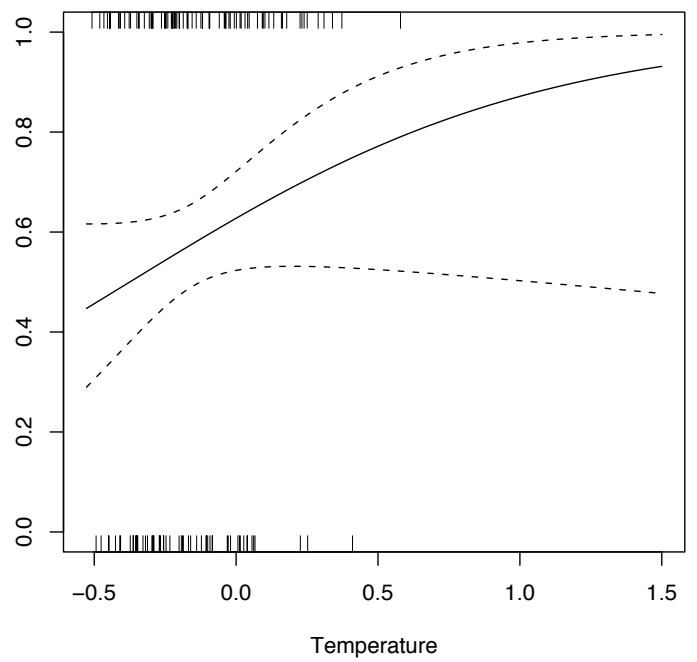

Figure 2: Probability of positive NAO as a function of temperature (logistic regression).

In order to get estimates for the number of deaths, affected people and damage, we first derived the expected rate of killed, affected people and damage per event. ${ }^{9}$ We then multiplied these figures by the expected number of events.

For each disaster type $d$ and region $r$ let $X_{d r}, Y_{d r t}$ be, respectively the number of events, the variable representing the burden of an event, and the total burden for year $t$, where burden may mean the number of persons killed, the number of persons affected or the per capita damage. The following relationship has been used: ${ }^{10}$

$$
E\left(Y_{d r t} \mid \mathrm{ENSO}_{t}, \mathrm{NAO}_{t}\right)=E\left(N_{d r t} \mid \mathrm{ENSO}_{t}, \mathrm{NAO}_{t}\right) E\left(X_{d r}\right)
$$

\section{A Modelling Framework}

To assess the systemic, general equilibrium effects of extreme events, we make an unconventional use of a multi-country world CGE model: the GTAP model (Hertel (1996)), in the version modified by Burniaux and Truong (2002), and subsequently extended by ourselves. The model structure is briefly described in the Appendix. ${ }^{11}$

\footnotetext{
${ }^{9}$ The average rate of killed and affected people was simply obtained as a mean. Because of missing observations, damage was instead obtained indirectly, using a linear regression between (log of) damage, (log of) deaths and (log of) affected people.

${ }^{10}$ Here we are implicitly assuming that $X$ and $N$ are independent, which is reasonable, and that $X$ is not affected by ENSO and NAO states.

${ }^{11}$ The GTAP model, and its variants, is very complex. Therefore, the description provided in the Appendix only sketches the overall model structure. More detailed information is available in the so-called "GTAP-
} 
This model is currently available in two versions: recursive dynamic and comparative static. The dynamic version generates a sequence of temporal equilibria, linked by capital and debt accumulation. The comparative static version is instead used to get counterfactual scenarios from baseline reference equilibria. A key characteristic of the static model is that the baselines refer to hypothetical equilibria in the future, rather than, as it is standard in the CGE methodology, to calibration equilibria in the past.

We derived benchmark data-sets for the world economy at selected future years (2010, 2030, 2050), using the methodology described in Dixon and Rimmer (2002). This entails inserting, in the model calibration data, forecasted values for some key economic variables, to identify a hypothetical general equilibrium state in the future. Since we are working on the medium-long term, we focused primarily on the supply side: forecasted changes in the national endowments of labour, capital, land, natural resources, as well as variations in factor-specific and multi-factor productivity. Most of these variables are "naturally exogenous" in CGE models. In some other cases we considered variables, which are normally endogenous in the model, by modifying the partition between exogenous and endogenous variables.

We obtained estimates of the regional labour and capital stocks by running the G-Cubed model (McKibbin and Wilcoxen (1998)). We got estimates of land endowments and agricultural land productivity from the IMAGE model version 2.2 (IMAGE (2001)). A rather specific methodology was adopted to get estimates for the natural resources stock variables. As explained in Hertel and Tsigas (2002), values for these variables in the original GTAP data set were not obtained from official statistics, but were indirectly estimated, to make the model consistent with some industry supply elasticity values, taken from the literature. For this reason, we computed stock levels in such a way that prices of natural resources vary over time, in the baseline scenario, in line with the GDP deflator.

\section{Consequences of Likelihood of Extreme Events in the Short Term}

What happens if, in the short run, no extreme event occurs, yet people get increasingly aware of the potential danger of natural disasters? First, prevention measures, like different building techniques, could be taken. Second, when risk cannot be reduced further, implicit or explicit insurance schemes could be adopted.

For example, people may buy insurance services on the market. Insurance companies make profits through arbitrage on risk propensity, but their role is basically the one of a financial intermediary: funds are collected and reinvested. Alternatively, people may save directly, by putting aside money for bad times. Another commonly seen measure is compulsory contribution to public insurance systems.

Like in the case of pensions, the aggregate effect of all these actions is similar: current consumption is reduced and savings first, then investments, are expanded. Since all these elements are included in final demand and GDP, in the short term everything

book" (Hertel (1996)), or on the technical references and papers available on the GTAP site (www.gtap.org). 
Table 1: Reference Regional Temperature Variations (2050)

\begin{tabular}{|c|c|}
\hline Region & $\Delta$ T (C.d.) \\
\hline USA & 1.43 \\
EU & 1.43 \\
EEFSU & 1.75 \\
JPN & 1.34 \\
RoA1 & 1.31 \\
EEx & 1.09 \\
CHIND & 1.23 \\
RoW & 1.04 \\
\hline
\end{tabular}

boils down to a different composition of demand structure in the economy. Industries like construction, or durable goods manufacturing, will benefit, whereas others (e.g., personal services) will suffer. In turn, relative competitiveness of all regions will change.

We simulate these effects in our CGE model by assuming that variations (positive or negative) in expected damage from extreme events translate into changes in savings, of the same order of magnitude. Equality between additional expected damage and savings, however, holds globally but not at the regional level, because of the existence of foreign aid, flowing from developed countries to developing countries.

Accordingly, we divide the world regions in two groups. A region $r$ in the set of developed countries (Europe - EU, USA, Japan - JPN, Rest of Annex 1 Countries $^{12}$ RoA1) will change its total domestic saving $\left(S_{r}\right)$ by:

$$
\Delta S_{r}=\Delta E D_{r}+\sigma_{r} \Delta F A
$$

where $E D_{r}$ is expected damage in region $r, F A$ is total foreign aid going to developing countries, and $\sigma_{r}$ is the share contribution of region $r$ to foreign aid funds, according to OECD (2003). On the other hand, a developing region $s$ (Eastern Europe and Former Soviet Union - EEFSU, Energy Exporters - EEx, China and India - CHIND, Rest of the World - RoW) will cover less than $100 \%$ of the expected damage:

$$
\Delta S_{s}=\phi_{s} \Delta E D_{s}
$$

where $\phi_{s} \leq 1$ is the coverage share ${ }^{13}$ and, of course:

$$
\Delta F A=\sum_{s}\left(1-\phi_{s}\right) \Delta E D_{s}
$$

We consider the effects of climate change on ENSO/NAO-sensitive extreme events, using 2050 as a reference year. To this end, we use estimates of regional temperature

\footnotetext{
${ }^{12}$ Annex 1 of the Kyoto Protocol on the reduction of greenhouse gases include developed (OECD) countries.

${ }^{13}$ This is also indirectly obtained from OECD data, on the basis of aid funds received by each country.
} 
Table 2: Expected Damages from Climate Change Induced Extreme Events (2050)

\begin{tabular}{|c|c|c|c|c|c|c|c|c|c|}
\hline Region & Drought & Epid. & Ex.Tem. & Famine & Flood & Slide & W. Fire & Wind S. & Total \\
\hline USA & & & & & 921 & & & & 921 \\
EU & & & & & -24 & & & 246 & 222 \\
EEFSU & & & & & & 7 & 258 & 45 & 309 \\
JPN & & & 11 & & & & -5 & & 7 \\
RoA1 & & & & & 77 & & & & 77 \\
EEx & -279 & 2 & 10 & 17 & -26 & & -18 & -11 & -306 \\
CHIND & & & 105 & & & & -79 & & 26 \\
RoW & -4 & 1 & 19 & 13 & -10 & & -16 & -44 & -39 \\
\hline
\end{tabular}

variations (2000-2050) $)^{14}$, reported in table $1 .{ }^{15}$ When this information is used in the statistical models, the relative frequency of ENSO and NAO states, the probability of extreme events, as well as the expected damage in each region is estimated. Variations in expected damage are readily obtained by comparing damage from extreme events with and without changes in average temperature.

Table 2 presents the estimated additional damage, for a set of catastrophic events, associated with the changed frequency of ENSO and NAO states. All values (in this and subsequent tables) are expressed in millions of US dollars. Zero values are set whenever the relationship, between frequency of events and ENSO/NAO state, is found to be not statistically significant.

We can see that impacts can be both positive and negative. On the negative side, the largest potential damage is generated by floods in the USA. Other significant dangers come from wind storms in Europe, wild fire in Russia and neighboring countries, and extreme temperatures in China and India. On the positive side, there are significant reductions of droughts in energy exporting countries and of wild fires in China and India.

Equations 4-6 translate variations in expected damage into higher or lower savings in each region. Changes in expected damage and savings are summarized in table 3.

Even if there are global expected damages in the world, total foreign aid funds decrease, because developing countries are supposed to experience less severe and frequent natural disasters. This result is mostly driven by expected benefits in energy exporting countries, getting a substantial fraction of aid funds. On the other hand, all developed regions need to save more to account for extra damage, although the increase in savings is partly compensated by reduced international donations.

The estimated variations in savings are used as an input in the CGE model, where domestic savings are adjusted upward or downward, and a new counterfactual equilibrium is computed for the world economy. Table 4 summarizes the output obtained from the model simulation, when savings in each region are forced to change according to the inputs of table 3 .

\footnotetext{
${ }^{14}$ Our elaborations from Giorgi and Mearns (2002).

${ }^{15}$ These values are consistent with IPCC scenarios, which report for 2050 an increase ranging from 0.5 to 2.5 Celsius degrees.
} 
Table 3: From Damage to Savings

\begin{tabular}{|c|c|c|c|c|c|c|c|}
\hline Region & Damage & Covered & Gives & Gets & $\Delta$ Sav. & $\phi$ & $\sigma$ \\
\hline USA & 921 & 921 & -76 & & 844 & - & 0.38 \\
EU & 222 & 222 & -78 & & 144 & - & 0.39 \\
EEFSU & 309 & 287 & & 23 & 287 & 0.93 & - \\
JPN & 7 & 7 & -9 & & -3 & - & 0.05 \\
RoA1 & 77 & 77 & -39 & & 38 & - & 0.19 \\
EEx & -306 & -88 & & -219 & -88 & 0.29 & - \\
CHIND & 26 & 22 & & 4 & 22 & 0.86 & - \\
RoW & -39 & -28 & & -11 & -28 & 0.72 & - \\
Total & 1216 & 1420 & -203 & -203 & 1216 & & 1.00 \\
\hline
\end{tabular}

Table 4: Impacts on Some Macro-economic Aggregates

\begin{tabular}{|c|c|c|c|}
\hline Region & G. D. P. & Invest. & Trade B. \\
\hline USA & -745 & 210 & 615 \\
EU & 141 & 317 & -176 \\
EEFSU & -266 & 14 & 279 \\
JPN & 348 & 238 & -227 \\
RoA1 & 19 & 57 & -18 \\
EEx & 230 & 173 & -249 \\
CHIND & 65 & 74 & -40 \\
RoW & 185 & 164 & -184 \\
\hline
\end{tabular}

When savings are increased (decreased), current consumption is decreased (increased), but national income is not directly affected. Since we are not simulating the economic impact of specific natural disasters, our exercise is mainly about the effects of a redistribution of resources. In particular, global savings increase in the world because the global damage is supposed to increase. As a consequence, investment in all regions increases as well. If a region receives less investment than its domestic savings, its trade balance will be positive (because of accounting identities). We can see in table 3 that this is the case of United States only.

Although there are no direct effects on the national income (GDP), the latter does change, because of variations in the world demand structure and in the terms of trade. The change is negative in USA, Eastern Europe and Former Soviet Union, and positive for all remaining regions. Negative effects are associated with investment outflows and net exports.

Interestingly, even if changes in the terms of trade are based on a sort of zerosum game for the regional economies (that is, a redistribution of world demand, under constant endowments of primary resources), estimated variations in the GDPs turn out to be of the same order of magnitude of expected damage (table 3), despite the fact that no damage is actually simulated here. 


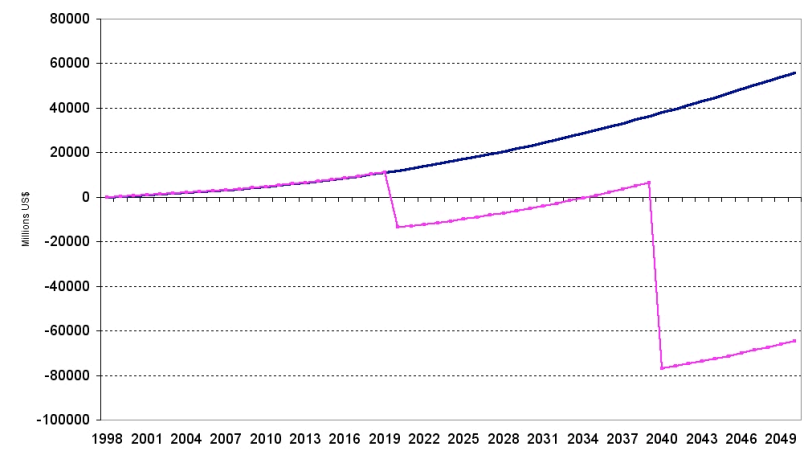

Figure 3: Additional capital stock accumulation in USA, with and without disaster losses.

\section{Consequences of Extreme Events on Regional Eco- nomic Growth}

Although changes in savings generate effects on the short run via changes in the demand structure, the primary consequence of different saving levels is on the long run, in terms of higher or lower economic growth. But these variations are, by construction, temporary.

For example, if people save more because they foresee a future damage, the economy will grow faster (since capital stock will accumulate faster), until the time when the adverse event materializes. Then, the economy will (temporarily) drop below the long run trend of growth. Analogously, if less damage is expected, the economy will grow slower, but in a smoother way.

We can see this effect in the dynamic version of the GTAP-EF model. Let us consider the case of the United States, for which the largest increment in damage is expected. As shown in table 3, this generates extra savings of 844 millions of dollars per year. In the model, we changed the marginal propensity to save (as a fraction of GDP), in order to reach this figure by the year 2050. Since most of additional savings are reinvested within the country ${ }^{16}$, there is a stronger growth in the capital stock, as displayed in figure 3. In this figure, the blue line shows the variation of capital endowments with respect to the baseline case, with no change in saving propensity. The red line shows the effects on capital stock of the faster accumulation, coupled with two big shocks (destroying capital), simulated at some arbitrarily chosen years. We can see that this makes the amount of extra capital stock oscillating around zero, which means that the increase in savings offsets, on average, the expected capital loss.

Since GDP may be measured as the value of primary resources in the economy, the variation of GDP at constant prices exhibits a similar trend, since capital is the only resource to change as a consequence of real or expected damages. If GDP is measured at current prices, instead, the value of capital decreases when capital becomes relatively

${ }^{16}$ In the simulations with the dynamic model, we restricted the degree of international capital mobility. 


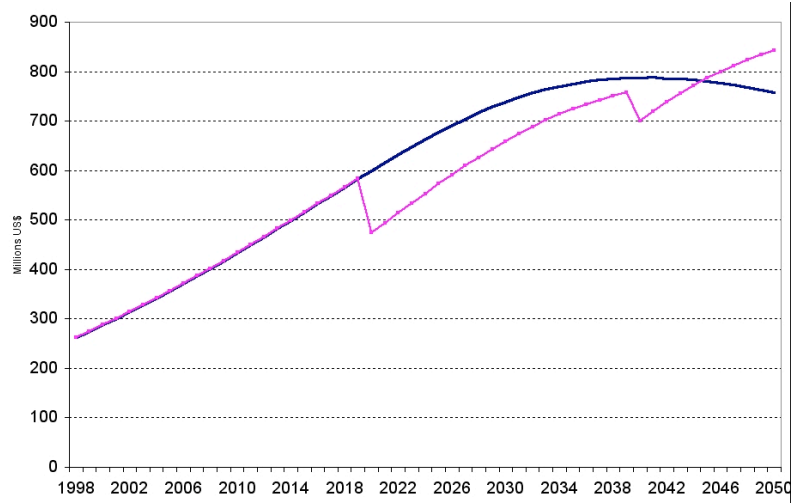

Figure 4: Additional savings in USA (current prices), with and without disaster losses.

abundant. The value of savings, which are a fraction of GDP, are affected by this price effect. Figure 4 shows the evolution of savings, measured at current prices, in the two scenarios of extra accumulation, with and without simulated disaster losses.

\section{Conclusion}

In this paper, we analyzed the economic impact of climate change in terms of extreme events and natural disasters. We have not considered the case of a major catastrophic event (like a collapse of thermoaline circulation), for which scientific evidence is insufficient. Rather, we focused on extreme phenomena (floods, hurricanes, etc.), that already affect several zones in the world, especially in tropical regions.

Climate change can potentially influence when and how natural disasters occur, possibly through its effects on the El Niño Southern Oscillation and the North Atlantic Oscillation. These are macro-scale phenomena, which in turn affect meso-scale variables, like regional wind circulation, humidity, etc. Climate scientists are actively studying these relationships, but a model directly linking climate change to local extreme weather conditions is not yet available. For this reason, we rely on a relatively simple statistical analysis, focusing on the correlation between ENSO/NAO states and extreme events, on one hand, and between temperature changes and oceanic circulation patterns, on the other hand.

Some links are found to be statistically significant, some others are not, but nonetheless all estimates are surrounded by uncertainty. Therefore, our simulation exercises are only meant to provide an illustrative analysis of the economic implications of higher or lower frequency of extreme events in different regions of the world.

From an economic point of view, we found that consequences are mainly of the distributional type, for two reasons. First, some extreme events will happen more often, some other events less often. Some regions will be hit more frequently, some other regions less frequently. Second, changes in the demand structure will be induced by 
increased or decreased likelihood of extreme events, thereby affecting regional competitiveness and the terms of trade.

We have also pointed out the implications of changing saving propensity on economic growth. Regions expecting more damage from extreme events will experience more variability in economic growth. On the other hand, regions expecting a reduced total burden from extreme events will exhibit a relatively steadier growth, around a long term trend.

\section{Acknowledgements}

This study is part of a project on economic modeling of climate change impacts, involving ICTP, FEEM and Hamburg University. Maria Berrittella, Francesco Bosello, Katrin Rehdanz, Richard S.J. Tol and Jian Zhang contributed with useful comments and discussions.

\section{References}

Bojariu, R. and Gimeno, L. Predictability and numerical modelling of the North Atlantic Oscillation. Earth-Science Reviews, 63:145-168, 2003.

M. Bouma, R. Kovats, S. Goubet, J. S. H. Cox, and A. Haines. Global assessment of El Niño's disaster burden. Lancet, 350:1435-38, 1997.

Burniaux J-M. and Truong, T.P., GTAP-E: An Energy-Environmental Version of the GTAP Model, GTAP Technical Paper n.16 (www.gtap.org), 2002.

Dickson, R.R. and Curry, R. and Yashayaev, I., Recent changes in the North Atlantic Philosophical Transactions Royal Society London A, 361:1917-1934, 2003.

Dixon, P. and Rimmer, M., Dynamic General Equilibrium Modeling for Forecasting and Policy, North Holland, 2002.

Giorgi, F. and L.O. Mearns, Calculation of average, uncertainty range and reliability of regional climate changes from AOGCM simulations via the "Reliability Ensemble Averaging" (REA) Method, American Meteorology Society, 15:1141-1158, 2002.

Gillett, N.P. and Zwiers, F.W. and Weaver, A.J. and Stott, P.A. Detection of human influence on sea-level pressure. Nature, 422:292-294, 2003.

T. Hastie and R. Tibshirani. Generalized Additive Models. Chapman and Hall, London, 1990.

Hertel, T.W., Global Trade Analysis: Modeling and Applications, Cambridge University Press, 1996.

Hertel, T.W. and Tsigas, M. , Primary Factors Shares, in GTAP Data Base Documentation, Chapter 18.c (www.gtap.org), 2002. 
Hoerling, M.P. and Hurrell, J.W. and Xu, T. Tropical origins for recent North Atlantic climate change. Science, 292:90-92, 2001.

A. Hunt. El Niño: Dynamics, its role in climate change, and its effects on climate variability. Complexity, 6(3):16-32, 2001.

Hurrell, J.W. Decadal trends in North Atlantic Oscillation: regional temperatures and precipitation. Science, 269:676-679, 1995.

IMAGE, The IMAGE 2.2 Implementation of the SRES Scenarios, RIVM CD-ROM Publication 481508018, Bilthoven, The Netherlands, 2001.

IPCC. Climate Change 2001: Impacts, Adaptation and Vulnerability. Cambridge University Press, UK, 2001.

S. Mason. El Niño, climate change, and Southern African climate. Environmetrics, 12(4):327-345, 2001.

McKibbin, W.J, Wilcoxen, P.J., The Theoretical and Empirical Structure of the GCubed Model, Economic Modelling, 16(1):123-48, 1998.

A. Meehl, F. Zwiers, J. Evans, T. Knutson, L. Mearns, and P. Whetton. Trends in extreme weather and climate events: issues related to modeling extremes in projections of future climate change. Bullettin of the American Metereological Society, 81(3):427436, 2000.

N. Nicholls. El Niño southern oscillation impact prediction. Bullettin of the American Metereological Society, 69(2):173-176, 1988.

OECD, Development Co-operation Report 2002 - Efforts and Policies of the Members of the Development Assistance Committee, The DAC Journal, 4(1), 2003.

Pauli, F., Disasters and ENSO, evidence from 1960-2001 disaster records, University of Trieste, Mimeo, 2004.

D. G. Sapir and R. Below. The quality and accuracy of disaster data. A comparative analysis of three global data sets. Working paper, Disaster research facility, World Bank, 2002.

P. Sardeshmukh, G. Compo, and C. Penland. Changes of probability associated with El Niño. Journal of Climate, 13(24):4268-4286, 2000.

Shindell, D.T. and Miller, R.L. and Schmidt, G.A. and Pandolfo, L. Simulation of recent northern winter climate trends by greenhouse-gas forcing. Nature, 399:425$455,1999$.

K. E. Trenberth. The definition of El Niño. Bullettin of the American Meteorological Society, 78(12):2771-2777, 1997.

Visbeck, M.H. and Hurrell, J.W. and Polvani, L. and Cullen, H.M. The North Atlantic Oscillation: past, present, and future. Proceedings of the National Academy of Sciences, 98(23):12876-12877, 1999. 
Wanner, H. and Brönniman, S. and Casty, C. and Gyalistras, D. and Luterbacher, J. and Schmutz, C. and Stephenson, D.B. and Xoplaki, E. North Atlantic Oscillation concepts and studies. Surveys in Geophysics, 22:321-382, 2001. 


\section{Appendix: A Concise Description of the GTAP-EF Model (Static and Dynamic)}

The GTAP model is a standard CGE static model, distributed with the GTAP database of the world economy (www.gtap.org).

The model structure is fully described in Hertel (1996), where the interested reader can also find various simulation examples. Over the years, the model structure has slightly changed, often because of finer industrial disaggregation levels achieved in subsequent versions of the database.

Burniaux and Truong (2002) developed a special variant of the model, called GTAPE, best suited for the analysis of energy markets and environmental policies. Basically, the main changes in the basic structure are:

- energy factors are taken out from the set of intermediate inputs, allowing for more substitution possibilities, and are inserted in a nested level of substitution with capital;

- database and model are extended to account for $\mathrm{CO}_{2}$ emissions, related to energy consumption.

The model described in this paper (GTAP-EF) is a further refinement of GTAP-E, in which more industries are considered. In addition, some model equations have been changed in specific simulation experiments. This appendix provides a concise description of the model structure.

As in all CGE models, GTAP-EF makes use of the Walrasian perfect competition paradigm to simulate adjustment processes, although the inclusion of some elements of imperfect competition is also possible. Industries are modelled through a representative firm, minimizing costs while taking prices are given. In turn, output prices are given by average production costs. The production functions are specified via a series of nested CES functions, with nesting as displayed in the tree diagram of figure 5. Notice that domestic and foreign inputs are not perfect substitutes, according to the so-called "Armington assumption", which accounts for product heterogeneity. In general, inputs grouped together are more easily substitutable among themselves than with other elements outside the nest. For example, imports can more easily be substituted in terms of foreign production source, rather than between domestic production and one specific foreign country of origin. Analogously, composite energy inputs are more substitutable with capital than with other factors.

A representative consumer in each region receives income, defined as the service value of national primary factors (natural resources, land, labour, capital). Capital and labour are perfectly mobile domestically but immobile internationally (although foreign investment is possible). Land and natural resources, on the other hand, are industry-specific.

This income is used to finance three classes of expenditure: aggregate household consumption, public consumption and savings (figure 6). The expenditure shares are generally fixed, which amounts to saying that the top-level utility function has a CobbDouglas specification. Also notice that savings generate utility, and this can be interpreted as a reduced form of intertemporal utility. Public consumption is split in a 


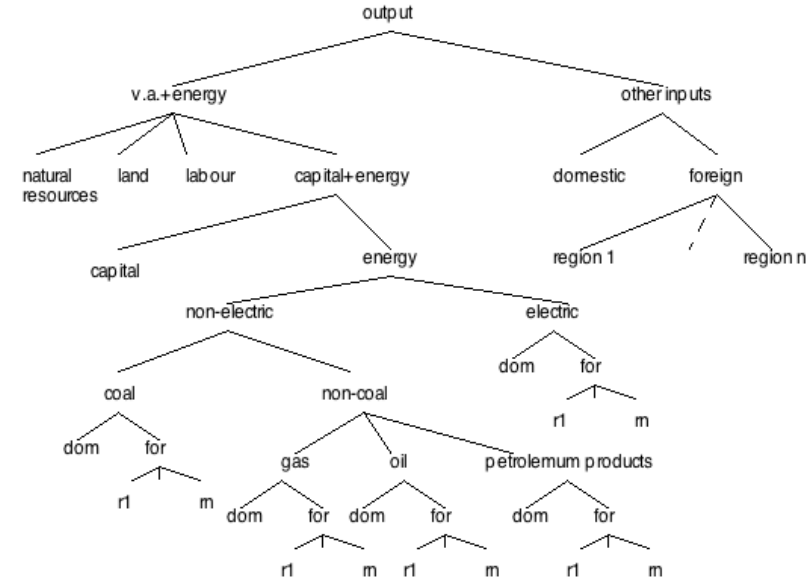

Figure 5: Nested tree structure for industrial production processes

series of alternative consumption items, again according to a Cobb-Douglas specification. However, almost all expenditure is actually concentrated in one specific industry: Non-market Services. Private consumption is analogously split in a series of alternative composite Armington aggregates. However, the functional specification used at this level is the Constant Difference in Elasticities form: a non-homothetic function, which is used to account for possible differences in income elasticities for the various consumption items.

In the GTAP model and its variants, two industries are treated in a special way and are not related to any country, viz. international transport and international investment production. International transport is a world industry, which produces the transportation services associated with the movement of goods between origin and destination regions, thereby determining the cost margin between f.o.b. and c.i.f. prices. Transport services are produced by means of factors submitted by all countries, in variable proportions.

In a similar way, a hypothetical world bank collects savings from all regions and allocates investments so as to achieve equality of expected future rates of return. Expected returns are linked to current returns and are defined through the following equation:

$$
r_{s}^{e}=r_{s}^{c}\left(\frac{K e_{s}}{K b_{s}}\right)^{-\rho}
$$

where: $r$ is the rate of return in region $s$ (superscript $e$ stands for expected, $c$ for current ), $K b$ is the capital stock level at the beginning of the year, $K e$ is the capital stock at the end of the year, after depreciation and new investment have taken place, $\rho$ is an elasticity parameter, possibly varying by region.

Future returns are determined, through a kind of adaptive expectations, from current returns, where it is also recognized that higher future stocks will lower future returns. 


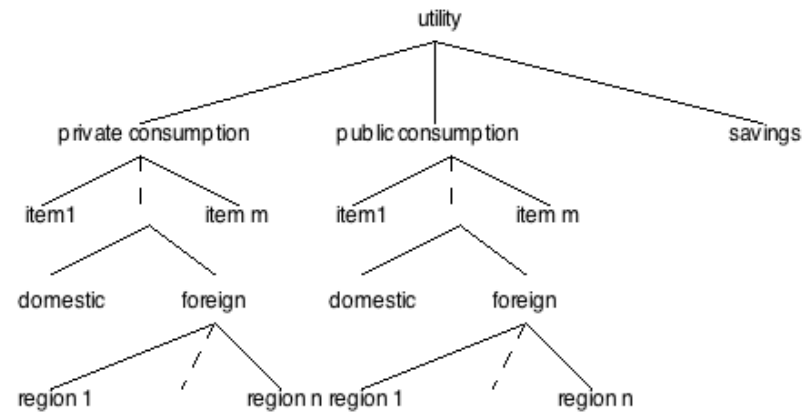

Figure 6: Nested tree structure for final demand

The value assigned to the parameter $\rho$ determines the actual degree of capital mobility in international markets. Since the world bank sets investments so as to equalize expected returns, an international investment portfolio is created, where regional shares are sensitive to relative current returns on capital. In this way, savings and investments are equalized at the international but not at the regional level. Because of accounting identities, any financial imbalance mirrors a trade deficit or surplus in each region.

A general equilibrium is said to exist if demand clears supply in all markets: goods, services and primary resources. Structural parameters of the model are calibrated, which amounts to assume that the world economy is in a hypothetical equilibrium state at a base year. Comparative static simulation exercise are performed by shocking exogenous variables and parameters.

A dynamic version of the model is obtained through generation of a series of equilibria. Equilibria differ because of exogenous dynamics in some parameters and variables (e.g., productivity, population) and of endogenous dynamics, due to capital and debt stock accumulation.

Capital stocks vary over time, on the basis of a standard capital accumulation equation:

$$
K e_{s}=K b_{s}(1-\delta)+I_{s}
$$

where $I_{s}$ are investments in region $s$, indirectly set by (7), and $\delta$ is the capital depreciation rate.

Debt stocks $(D e, D b)$ cumulate in a similar way, according to:

$$
D e_{s}=D b_{s}+\left(M_{s}-X_{s}\right)
$$

where $M_{s}$ and $X_{s}$ are, respectively, total value of imports and exports of region $s$ in a given period.

The existence of debt stocks, positive or negative, generates flows of interest payments among regions, which are treated in the model like international income transfers. By construction, the sum of all debt stocks in the world is identically equal to zero in all periods. 